\title{
PROCESSOS E SENTIDOS DA REGULAÇÃO TRANSNACIONAL DA PROFISSÃO DOCENTE: uma análise das Cimeiras Internacionais sobre a Profissão Docente (2011-2017)
}

\author{
Marta Almeida \\ Instituto de Educação, Universidade de Lisboa \\ Joana Viana \\ Instituto de Educação, Universidade de Lisboa \\ Luís Miguel Carvalho \\ Instituto de Educação, Universidade de Lisboa
}

\begin{abstract}
Resumo
O artigo analisa os modos como, em um cenário de intensificação e sofisticação dos processos de regulação transnacional em educação, se concretiza a intervenção de organizações periciais no plano da regulação da profissão docente. Incidindo, em particular, nas Cimeiras Internacionais sobre a Profissão Docente, organizadas sob a égide da Organização para a Cooperação e Desenvolvimento Económico (OCDE), procura perceber, ora como são erigidos e priorizados os desafios que se colocam ao exercício da profissão docente à escala global, ora como são equacionadas as resoluções a ratificar por atores nacionais. $\mathrm{O}$ estudo revela uma dileção pelo paradigma comparativista da educação na condução das Cimeiras, ancorada no recurso a conhecimento pericial produzido em estudos de larga escala. Deste processo resulta a construção de um 'argumentário' que atesta a existência de problemas à escala global a carecer de intervenção urgente, e a sinalização 'de boas práticas’ que servem de referentes para as decisões a adotar.
\end{abstract}

Palavras-chave: Cimeira Internacional sobre a Profissão Docente; conhecimento pericial; OCDE; políticas sobre a profissão docente; regulação transnacional

\begin{abstract}
The article analyzes the ways in which, in a scenario of intensification and sophistication of transnational regulation processes in education, this intervention occurs at the level of regulation of the teaching profession. It focuses on the analysis of Organization for Economic Cooperation and Development (OECD) International Summits. We seek to understand how the challenges faced by the teaching profession at global level are raised and prioritized, and also how the resolutions to be adopted are considered by national actors. The study reveals a preference for the comparative paradigm of education in conducting the Summits, anchored in the use of expert knowledge produced in large-scale studies. This process results in the construction of an argument that attests the existence of a problem in need urgent intervention on a global scale, and in signaling the 'best practices' that point to the solution to be addressed.
\end{abstract}

Keywords: expert knowledge; International Summit on the Teaching Profession; OECD; teacher policies; transnational governance. 


\section{Introdução}

No quadro crescente protagonismo de diversas organizações internacionais (OI) nos processos de regulação transnacional em educação (OZGA; LINGARD, 2007) tem sido notada a ampliação da intervenção da Organização para a Cooperação e Desenvolvimento Económico (OCDE), visível ora na estruturação de mecanismos cada vez mais sofisticados de convocação de diversos atores à preleção em torno de problemas que coloca na ordem do dia, ora na produção de conhecimento pericial que desempenha o papel de informar e legitimar as ideias postas a circular em fóruns nacionais e internacionais (CARVALHO, 2016). É neste cenário que a OCDE instiga e/ou patrocina fóruns de discussão a nível internacional, emergentes arenas políticas nas quais têm lugar discussões em torno das tensões e preocupações decorrentes de problemas que são associados à qualidade da educação, à escala global. Tais discussões são geralmente suportadas pelo conhecimento pericial produzido pela própria OCDE (e.g. através do Teaching and Learning International Survey - TALIS - e o Programme for International Student Assessment - PISA).

Este artigo incide sobre a intervenção da referida organização internacional na esfera da regulação da profissão docente, por via de uma análise das orientações sobre a formação docente elaboradas no quadro das Cimeiras sobre a Profissão Docente (International Summit on the Teaching Profession) - doravante, Cimeira(s) -, realizadas sob a égide da OCDE desde 2011. Essas proposições são analisadas enquanto manifestações da regulação transnacional (OZGA; LINGARD, 2007; DJELIC; SAHLIN-ANDERSON, 2006) das políticas de formação de professores. Intenta-se (i) desocultar os processos de mobilização e coordenação dos atores nestes fóruns internacionais, bem como (ii) identificar, descrever e interpretar as proposições sobre a formação docente produzidas e difundidas nas referidas Cimeiras: (a) as suas problematizações, isto é, o processo através do qual genericamente, se apresenta uma linha de argumentação que delimita e põe em evidência a existência de um problema comum, a que também coletivamente urge dar resposta; (b) as suas preconizações, isto é, a atividade de procura concertada de soluções para os problemas erigidos (e supostamente partilhados pelos atores), através de processos de aproximação sucessiva àquelas que deverão ser as linhas de atuação a adotar (DELVAUX, 2009).

No plano metodológico, o estudo baseia-se em dois conjuntos de documentos produzidos para e após as Cimeiras. O primeiro conjunto documental integra os documentos preparatórios produzidos pela OCDE. O segundo conjunto, principal foco da análise efetuada, integra os relatórios síntese gerados após os referidos encontros, sob a chancela da Asia Society Partnership for Global Learning (AS) ${ }^{1}$.

O texto organiza-se em três secções. A primeira ocupa-se da discussão das Cimeiras sobre a profissão docente enquanto analisador de processos de regulação transnacional das políticas educativas. A segunda dedica-se à descrição e análise dos processos de coordenação dos atores que participam nos referidos fóruns, incidindo, nomeadamente na estrutura organizativa dos encontros e na convocação dos atores, na identificação dos participantes e dos papéis por estes desempenhados, e ainda observando o lugar das Cimeiras enquanto plataforma desencadeadora de reformas à escala global com reflexos nas políticas nacionais. 
Prossegue-se, na terceira secção, com uma análise dos modos de emergência dos problemas e respetivas preconizações, visando a identificação quer dos problemas centrais, quer dos que lhe são subsidiários, bem como das soluções e linhas orientadoras da ação gizadas, analisando o recurso às narrativas em torno das 'boas práticas' tidas como casos exemplares ou modelos inspiradores, e a mobilização de conhecimento pericial na/para a obtenção de consensos. Encerra-se com a exposição das principais linhas interpretativas e conclusivas alcançadas.

\section{Os Teacher Summits como analisadores de processos de regulação: esquiço da problemática e metodologia}

As OI vêm alargando o seu âmbito de ação nos processos de multirregulação da educação (BARROSO, 2005), atingindo as políticas públicas nacionais, quer difundindo ideias e normas acerca de estruturas, processos e práticas educativas; quer construindo novos espaços e novos instrumentos para o exercício do governo (LEUZE; MARTENS; RUSCONI, 2007; RIZVI; LINGARD, 2006). No caso da OCDE, essa intervenção, exercida em - e sobre vários subsistemas sociais, entre os quais os educativos, exerce-se idealizando, agregando atores, supervisionando interdependências (MARCUSSON, 2004). No campo da educação, esse modus operandi observa-se tanto no plano da produção de problematizações e preconizações sobre os sistemas educativos, quanto no plano da organização de relações de interdependência entre os atores que intervêm nos processos de regulação da educação (CARVALHO, 2016). São estas as duas dimensões da ação no espaço das políticas da profissão docente em que incide este artigo.

A intervenção das OI vem afetando as políticas sobre a profissão docente e a sua formação (BEIJAARD; MEIJER; MORINE-DERSHIMER; TILLEMA， 2005; ROBERTSON, 2012). A intensificação do papel das instâncias e dos fóruns internacionais nos processos de regulação das políticas sobre a profissão docente e a formação de professores faz com que estas sejam até referenciadas como key-players (CARVALHO; NORMAND, 2018, p.1). Entre estas conta-se a OCDE que, recorrendo ao conhecimento pericial gerado por inquéritos de larga escala, como o TALIS e o PISA, vem dinamizando anualmente espaços organizados para o debate da profissão docente, nos quais enfatiza, por um lado, a importância das políticas educativas e das políticas sobre a profissão docente para a melhoria da qualidade dos sistemas educativos, e, por outro lado, se acentua a premência de processos de convergência internacional em torno dessas políticas.

As Cimeiras sobre a profissão docente e a sua formação são organizadas sob a égide da OCDE desde $2011^{2}$ (quadro 1) e publicitadas como um espaço ímpar para um diálogo permanente sobre a profissão docente (AS, 2011). 
Quadro 1 - Cimeiras realizadas entre 2011 e 2017 e respetivos temas.

\begin{tabular}{|l|l|l|}
\hline \multicolumn{2}{|c|}{ Temas das Cimeiras realizadas entre 2011 e $\mathbf{2 0 1 7}^{3}$} & \multicolumn{1}{c|}{$\begin{array}{c}\text { País de } \\
\text { acolhimento }\end{array}$} \\
\hline $\mathbf{2 0 1 1}$ & Improving teacher quality around the world & EUA \\
\hline $\mathbf{2 0 1 2}$ & Teaching and leadership for the twenty-first century & EUA \\
\hline $\mathbf{2 0 1 3}$ & Teacher Quality & Holanda \\
\hline $\mathbf{2 0 1 4}$ & Excellence, Equity, and Inclusiveness. High Quality Teaching for All & Nova Zelândia \\
\hline $\mathbf{2 0 1 5}$ & Implementing Highly Effective Teacher Policy and Practice & Canadá \\
\hline $\mathbf{2 0 1 6}$ & $\begin{array}{l}\text { Teachers' professional learning and growth: } \\
\text { creating the conditions to achieve quality teaching for excellent learning } \\
\text { outcomes }\end{array}$ & Alemanha \\
\hline $\mathbf{2 0 1 7}$ & $\begin{array}{l}\text { Empowering and Enabling Teachers to Deliver Improved Equity and Outcomes } \\
\text { for All }\end{array}$ & Escócia \\
\hline
\end{tabular}

Na divulgação destes encontros, a OCDE coloca a tónica na premência de dar destaque à profissão docente e, concomitantemente, na necessidade de uma forte implicação dos professores nas reformas educativas, apresentando a ideia de uma missão coletiva a empreender na procura de soluções para problemas expostos como transversais aos sistemas educativos de todo o mundo (ver AS, 2011-2017). De uma forma genérica, as problematizações avançadas são apresentadas sob a forma de questões urgentes a carecer de reflexão conjunta, problemas que ficam evidenciados não só a partir de proposições genericamente apresentadas como perceções e representações de atores provenientes de diferentes sectores (político, académico, profissional), apoiando-se também fortemente em conhecimento pericial, produzido através de estudos de larga escala desenvolvidos sob a égide da OCDE. A OCDE identifica, desde logo, nos documentos preparatórios que informam as Cimeiras, movimentos de reforma nos sistemas à escala global, em linha com as preocupações que presidem a organização das Cimeiras. Esses movimentos de reforma têm como principal propósito, segundo a OCDE, "garantir uma melhor preparação das crianças para os cada vez mais exigentes desafios da vida e do trabalho no século XXI" (SCHLEICHER, 2012, p.3.). A narrativa é desenvolvida reforçando a ideia de que os desafios da aprendizagem para o séc. XXI implicam novas conceções de ensino e de aprendizagem, diferentes papéis para professores e alunos face aos tradicionalmente atribuídos, o que, inevitavelmente, terá implicações nos modos como o profissionalismo e a profissionalidade docente são balizados (ver e.g. AS, 2013, 2016). A intenção declarada das Cimeiras é, então, a de identificar as linhas de atuação a desenvolver, para que se possa melhorar a qualidade do exercício profissional docente. A titulação dos documentos preparatórios do primeiro encontro - "Construir uma profissão docente de elevada qualidade. Lições à volta do globo"4 — ilustra claramente este propósito.

O recurso a diferentes modos de regulação soft das políticas educativas (JACOBSSON, 2006) está presente nas Cimeiras, nomeadamente, favorecendo contextos "meditativos" e "exortativos" (JACOBSSON, 2006; BRADFORD, 2008). Por um lado, o ambiente 
meditativo é gizado por forma a criar condições favoráveis à emergência da agenda préfixada, onde o conteúdo substantivo subjacente às questões a tratar vai sendo gradualmente exposto, convocando à reflexão conjunta (JACOBSSON, 2006). Por outro lado, tendo subjacente o postulado de que há que pensar globalmente para agir à escala local, é incrementado um ambiente exortativo, em que os participantes são incitados a assumir publicamente, não só a concordância com as linhas de atuação esboçadas, como também a avançar com compromissos de ação nos contextos de onde provêm (BRADFORD, 2008). Ilustra esta ideia o trecho exortativo seguinte:

se os encontros internacionais podem ser descritos como 'game changers', então, este é certamente um deles. A Cimeira de 2011 foi bem-sucedida na demonstração de que até problemas aparentemente intratáveis podem ser resolvidos em diferentes países em todo o mundo (AS, 2012, p.3).

Este texto, resultante de um estudo mais vasto sobre as orientações sobre a formação docente elaboradas a nível internacional, no quadro Cimeiras sobre a Profissão Docente, realizadas sob a égide da OCDE (ALMEIDA; VIANA, 2019) ${ }^{5}$, interroga as Cimeiras em dois planos: (a) nos processos de coordenação dos atores que são postos em marcha através - e nestes - fóruns internacionais organizados sob a égide da OCDE; as agendas que os constituem. Neste segundo plano analítico, o estudo procura identificar e descrever as proposições sobre a formação docente produzidas e difundidas nas Cimeiras realizadas entre os anos de 2011 e 2017, enquanto manifestações da regulação transnacional das políticas de formação de professores.

Consequentemente, a inquirição compreende duas dimensões: uma, de natureza descritiva e interpretativa, onde se faz a apresentação das Cimeiras Internacionais através da sua inscrição nos processos de intensificação e sofisticação da intervenção reguladora da OCDE sobre as políticas nacionais a partir dos resultados de grandes inquéritos que dirige, e que permitem gerar problematizações e preconizações sobre a formação de professores; outra, de caráter eminentemente interpretativo, desdobra-se numa análise relativa às 'narrativas' (PETTERSON; MØLSTAD 2016) desenvolvidas sobre a profissão docente no contexto meditativo e exortativo (JACOBSSON, 2006; BRADFORD, 2008) das Cimeiras e numa outra atenta às regras (orientações e justificações de ação) que 'induzem’ para as políticas nacionais.

As análises aqui desenvolvidas decorrem da composição e do tratamento de um acervo documental com dois conjuntos de documentos: os relatórios gerados por cada Cimeira (2011 a 2017) e publicados sob a chancela da Asia Society Partnership for Global Learning (AS); partes dos relatórios elaborados pela OCDE, para cada Cimeira, a partir de estudos como o TALIS e o PISA, e cuja função é a de apoiar a atividade 'reflexiva' entre os atores presentes (políticos, peritos e representantes dos professores, entre outros). Para tratamento e análise dos dados recorreu-se à técnica de análise de conteúdo (BARDIN, 2009), enquanto processo de hermenêutica controlada baseado na dedução, e visando a desocultação do sentido latente, o que permite a classificação e interpretação dos elementos dos textos que não são passíveis 
de ser obtidos apenas através de uma leitura espontânea (GHIGLIONE et al., 1980; ROBERT; BOUILLAGUET, 2002).

A análise efetuada, e atendendo aos objetivos que nortearam o estudo, estruturou-se em torno das duas dimensões atrás referidas, que orientarão a apresentação e discussão dos resultados nas secções seguintes. A primeira dimensão abarca os processos de coordenação e desdobra-se em três partes: (i) estrutura organizativa dos encontros e à convocação dos atores; (ii) atores presentes e papéis atribuídos; (iii) fóruns enquanto plataforma desencadeadora de reformas à escala global com reflexos nas políticas nacionais. A segunda dimensão visa os processos de problematização e preconização, subdividindo-se em quatro planos: (i) problemas centrais e subsidiários; (ii) preconizações e linhas orientadoras da ação avançadas; (iii) ‘boas práticas’ partilhadas como casos exemplares ou modelos inspiradores; (iv) mobilização de conhecimento pericial na/para a obtenção de consensos.

\section{Os processos de coordenação nas Cimeiras Internacionais sobre a Profissão Docente}

\section{Estrutura organizativa e convocação dos atores}

A organização das Cimeiras envolve três grandes operações: (i) o lançamento de questões que suportam a problematização dos desafios que os sistemas educativos enfrentam e que, para os promotores, são o foco central do encontro; (ii) a difusão dos resultados obtidos em estudos de larga escala que informam as discussões nos diferentes momentos e nos vários grupos de trabalho; (iii) a articulação - em contextos de copresença - entre os resultados dos estudos de larga escala e a partilha de experiências na voz de atores diversificados e com intervenção em diversos setores - político, económico, académico, profissional.

Paralelamente, existe um trabalho de convocação dos atores para as Cimeiras que é discursivamente dirigido pela disposição de sentar à mesma mesa, a nível internacional, ministros e representantes das associações profissionais (AS, 2012). Sublinha-se a necessidade de articular perspetivas e interesses de diferentes stakeholders para que as soluções preconizadas possam efetivamente ser implementadas e, assim, serem bemsucedidas. Enfatiza-se, na retórica da OCDE, o papel ativo a conceder ou esperar dos professores como agentes de reforma, sendo referido que "as reformas não funcionam se forem introduzidas de cima para baixo - se os professores forem tratados apenas como 'parte do problema'. Os professores têm que ser centrais nas soluções; neste sentido as associações de professores podem ser poderosos aliados" (AS, 2012, p. 4).

Entre 2011 e 2017, as Cimeiras mobilizaram atores provenientes de diversos setores para o desenvolvimento dos trabalhos, nomeadamente: da OCDE; um comité do país anfitrião (geralmente integrando altos quadros nas estruturas governamentais); delegações dos países convidados a partilhar as suas experiências (entre estes encontram-se atores com cargos oficiais nos governos locais e, ocasionalmente, são convidados diretores e/ou professores de escolas de referência, de centros de formação e especialistas de reconhecido mérito); 
representantes de organizações profissionais, destacando-se aqui o lugar do Secretário-Geral da Education International (ver anexo 1).

\section{Atores e (seus) papéis}

Decorrente da estratégia explicitada anteriormente, a proveniência dos participantes é diversa, representando variados contextos nacionais e organismos e organizações (estatais e não estatais), sendo também distintos os papéis a que são alocados nos trabalhos. Assim, a uns são atribuídos papeis de interventores, que desempenham papéis pré-definidos nos diferentes momentos dos trabalhos, e outros o de audientes ou espectadores.

No conjunto de interlocutores interventores encontramos três grandes tipos de atores: os provenientes da OCDE enquanto entidade organizadora; os académicos e as delegações dos países convocados a partilhar as suas experiências.

Aos representantes da $\mathrm{OCDE}^{6}$ cabe abrir e orientar os trabalhos, expondo as grandes questões, justificando a existência de problemas e dilemas que fragilizam a qualidade dos sistemas educativos e que são transversalmente sentidos por professores dos diversos países participantes.

Aos académicos - académicos de mérito reconhecido à escala internacional ${ }^{7}$, de geografias e afiliações institucionais diversas - cabe moderar as intervenções e também, juntamente com os anteriores, sistematizar os principais consensos e linhas de força identificadas, realçar as divergências ainda existentes, bem com traduzir essas conclusões em recomendações ou caminhos a seguir e exortar os países participantes a assumir compromissos de atuação futura. Desde a terceira Cimeira (2013), o papel dos académicos é alargado ao de formadores. Com efeito, os encontros passam a incorporar momentos de formação na modalidade de workshop, desenvolvidos em torno das linhas de ação que vão sendo defendidas ao longo do encontro, e ganham um novo suporte através da sua sustentação em conhecimento gerado pela investigação científica.

Aos 'dignatários' dos países participantes (ver anexo 1), cabe partilhar trajetórias experienciadas e 'boas práticas' introduzidas nas políticas públicas dos seus países ${ }^{8}$. A escolha destes representantes nacionais obedece a três critérios que outrossim sinalizam os valores de mérito consagrados pela OCDE: atores que reconhecem a existência do problema em análise nos seus sistemas educativos, que adotam orientações políticas que enquadram as preconizações avançadas ao longo da cimeira e que são considerados casos de "sistemas educativos com melhorias acentuadas e elevado desempenho ” (SCHLEICHER, 2011, p.11), distinção obtida a partir do posicionamento alcançado nos estudos de larga escala conduzidos pela OCDE (como são exemplo o PISA e o TALIS).

Assim, o papel atribuído a este terceiro grupo de atores é o de portadores e informantes das 'boas práticas adotadas', produzindo narrativas em torno dos processos de construção e receção das políticas (nacionais ou regionais), sustentando a eficácia das suas opções quer em indicadores de desempenho obtidos a partir de sistemas de monitorização implementados a nível nacional, quer em indicadores provenientes de estudos comparativos internacionais. As suas intervenções servem de base a uma discussão mais alargada ${ }^{9}$ em que os restantes 
atores presentes nas Cimeiras - os audientes ou espetadores sem intervenção formalizada na agenda de trabalho - possam, nestes espaços, intervir de forma espontânea. A partir de 2013, as Cimeiras passam a prever momentos de trabalho por delegação nacional, apresentados como vocacionados para a partilha de reflexões por audientes ou espetadores. Estes momentos culminam com a apresentação pública de um compromisso assumido por cada um dos países participantes na Cimeira na senda das linhas de ação acordadas.

\section{Os fóruns como plataforma para gerar uma reforma global e políticas nacionais}

As Cimeiras são apresentadas como espaços de partilha e de procura de soluções comuns para problemas globais. A estratégia que preside à organização dos encontros agrega uma multiplicidade de atores, com diferentes responsabilidades e proveniências, que em conjunto delineiam regras para a ação coletiva de orientação reformista. A existência de regras formais e informais, que enquadram e estatuem o modo como os atores interagem entre si, revelam modos híbridos de coordenação da ação coletiva, combinando o ajustamento mútuo, o reconhecimento de níveis de autoridade diferenciados, e em que se delibera com base em processos de negociação e concertação.

Para a OCDE, no contexto da sua intervenção nos processos de governança transnacional, as Cimeiras constituam espaços onde os diferentes atores, com distintos interesses e papéis confluem, reconhecendo, desta forma, a interdependência dos mesmos nos processos de construção das políticas educativas e de formação de professores. Neste cenário, é expressamente anunciada a preocupação em promover a articulação de perspetivas de diversos stakeholders, para que as soluções preconizadas sejam implementadas e, desse modo, serem bem-sucedidas. Como é sublinhado desde o primeiro momento, a estratégia que encabeça a organização das Cimeiras permitirá revelar "como um modelo colaborativo de reforma educacional pode ser altamente eficaz” (SCHLEICHER, 2011, p.11).

A ideia de que as Cimeiras serão o espaço privilegiado para, coletivamente, encontrar linhas de atuação à escala supranacional emerge, igualmente, nos documentos da AS, salientando-se a possibilidade de aprendizagem coletiva proporcionada pelas Cimeiras, que são apresentadas como "uma sala de aula que espelha a diversidade a nível internacional, juntando diferentes perspetivas em torno da consecução de objetivos comuns - excelentes professores e escolas eficazes para todas as crianças” (AS, 2011, p. 6).

A narrativa de produção colaborativa de reformas desenvolve-se em documentos como o relatório da Asia Society de 2016 no qual é enaltecido o contributo das Cimeiras, apresentadas como fóruns únicos no seu género, devotados à discussão e partilha de ideias, capazes de impulsionar os países não só para o diálogo, como também para a ação. No caso dos países que, de forma regular, participam nos encontros, são sublinhados os contributos específicos e a possibilidade de poderem refletir sobre o seu progresso. Para os países que participam pela primeira vez, é elogiada a oportunidade de aprenderem com os sucessos e fracassos dos outros. Finalmente, o impacto das Cimeiras nas políticas domésticas é publicitado no início de cada encontro (ver e.g. AS, 2012, 2014, 2016). Por exemplo, na 
sessão de abertura da Cimeira de 2012 é referenciada a reforma "RESPECT”, levada a cabo pelos Estados Unidos, em consequência dos trabalhos desenvolvidos na Cimeira anterior:

Na abertura da Cimeira, o Secretário Geral da Educação dos Estados Unidos, Arne Ducan, reconhece o impacto da primeira Cimeira, que ajudou a configurar um novo, e sem precedentes, programa de 5 biliões de dólares, com o propósito de fortalecer e valorizar a profissão docente nos Estados Unidos, designado RESPECT - for Recognizing Educational Success (AS, 2012, p. 3).

Em síntese, nas Cimeiras, são criadas condições para que atores provenientes de diferentes sectores e de contextos nacionais com percursos variados possam, em conjunto, refletir sobre os sistemas educativos e a profissão docente enquanto objetos universais. Através de discussões e negociações alargadas são apresentados problemas e soluções, visando a procura de consensos e, que portadores desse estatuto, possam verter para orientar as políticas nacionais.

\section{Processos de problematização e preconização: narrativas, conhecimento pericial, 'boas práticas' e consensos}

O acervo documental analisado permite examinar os modos como a formação e a profissão docente - a carreira docente e o trabalho docente - são apresentadas como problemas que carecem de reflexão e de intervenção por parte das autoridades públicas nacionais - i.e. problematizações - e como são construídas e apresentadas as soluções a prosseguir - i.e. preconizações. A argumentação vai sendo construída para que, a partir dos problemas entendidos como questões globais e urgentes a carecer de uma resposta coletiva, as soluções sejam encontradas através de processos de concertação da direção a seguir. Com efeito, ao longo da Cimeira vão sendo equacionadas, selecionadas e firmadas linhas de atuação comuns. Estes processos de convocação à construção de consensos, embasam numa triangulação de fontes: o conhecimento pericial continuamente exibido; os resultados provenientes da investigação em contexto académico; as narrativas produzidas pelos países de elevado desempenho, a propósito das trajetórias experienciadas e da adoção de 'práticas' que se revelam promissoras.

\section{Problematizações}

Os processos de problematização têm início na própria fundamentação para a necessidade de realizar as Cimeiras. Esta necessidade é sustentada por duas linhas de argumentação. Uma sobre a ideia sistema social - sistema educativo; outra sobre a formação de professores para os idealizados sistemas educativos. Por um lado, a invocação das mudanças que estão a ocorrer a uma escala mundial, apresentadas como fruto de fenómenos de rápida transformação social e dos mercados de trabalho no séc. XXI, aliados a fenómenos 
de aceleração na produção, circulação e acesso ao conhecimento, bem como a novos modos de relação com o conhecimento a que os sistemas educativos precisam de dar resposta. Por outro lado, a advocação da ideia segundo a qual as soluções para os novos desafios que os sistemas educativos enfrentam dependem, em grande medida, da capacidade para repensar e transformar a profissão docente pois que, nesta ordem das ideias, o professor é o fator com maior impacto nas aprendizagens dos alunos.

Por economia de espaço, apresenta-se apenas uma síntese dos problemas centrais e subsidiários (os que são apresentados na abertura das Cimeiras como derivações do problema principal enunciado) inscritos nas agendas de trabalho ao longo das Cimeiras (quadro 2).

Em grande parte das Cimeiras, o conhecimento proveniente de estudos de larga escala desenvolvidos pela OCDE (TALIS e PISA) é mobilizado para sustentar a existência dos problemas em análise, recorrendo-se ainda a outros indicadores estatísticos de avaliação comparada que permitem reforçar a ideia de que se está perante um problema globalizado e comum, independentemente de poder ser mais acentuado em uns contextos do que em outros. São ainda estabelecidas relações de causa-efeito, tendo em vista a procura de soluções que permitiam atuar nessa atribuição causal.

Quadro 2. Problematizações: problemas centrais e problemas subsidiários.

\begin{tabular}{|c|c|c|}
\hline $\begin{array}{l}\text { PROBLEMA } \\
\text { CENTRAL }\end{array}$ & CIMEIRAS & QUESTÕES SUBSIDIÁRIAS (exemplos) \\
\hline $\begin{array}{l}\text { Como garantir um } \\
\text { sistema com } \\
\text { professores de } \\
\text { elevada qualidade? }\end{array}$ & $\begin{array}{l}2011,2013, \\
2014,2015, \\
2016,2017\end{array}$ & $\begin{array}{l}\text { - O que se entente por professores de qualidade? } \\
\text { - Que processos e procedimentos de recrutamento, captação e preparação de } \\
\text { professores de elevada qualidade? } \\
\text { - Como estabelecer sistemas apoio e desenvolvimento profissional de } \\
\text { qualidade? } \\
\text { - Como monitorizar e avaliar a qualidade dos professores e promover a sua } \\
\text { articulação com a melhoria da escola? }\end{array}$ \\
\hline $\begin{array}{l}\text { Como garantir o } \\
\text { ensino de alta } \\
\text { qualidade para todos: } \\
\text { excelência, equidade } \\
\text { e inclusão? }\end{array}$ & $\begin{array}{l}\text { 2014, 2015, } \\
2017\end{array}$ & $\begin{array}{l}\text { - Como captar professores e líderes de elevada qualidade para as Escolas } \\
\text { com maiores dificuldades? } \\
\text { - Como se alcança a equidade em sistemas educativos cada vez mais } \\
\text { desenvolvidos e descentralizados? } \\
\text { - Como desenvolver de ambientes de aprendizagem que atendam às } \\
\text { necessidades de todos e promovam a excelência e a equidade dos } \\
\text { resultados? }\end{array}$ \\
\hline $\begin{array}{l}\text { Como estabelecer } \\
\text { uma liderança e } \\
\text { prática profissional } \\
\text { altamente eficaz? }\end{array}$ & $\begin{array}{l}2012,2014, \\
2015,2016, \\
2017\end{array}$ & $\begin{array}{l}\text { - Como desenvolver formas modernas de liderança na educação? } \\
\text { - Como preparar os líderes escolares? } \\
\text { - Como promover a inovação para criar ambientes de aprendizagem para o } \\
\text { desenvolvimento de competências para o séc. XXI? } \\
\text { - Que políticas de apoio deverão ser promovidas para que os professores } \\
\text { adquiram as competências necessárias face aos novos desafios? } \\
\text { - Como valorizar os professores? }\end{array}$ \\
\hline $\begin{array}{l}\text { Como incrementar a } \\
\text { aprendizagem e } \\
\text { desenvolvimento } \\
\text { profissional dos } \\
\text { professores? }\end{array}$ & $\begin{array}{l}2011,2012, \\
2013,2015, \\
2016,2017\end{array}$ & $\begin{array}{l}\text { - Como preparar os professores para criarem ambientes de aprendizagem do } \\
\text { sec. XXI? } \\
\text { - Quais os conhecimentos, capacidades e atitudes necessários aos } \\
\text { professores de sucesso, para um ensino eficaz no mundo globalizado e } \\
\text { tecnológico do século XXI? }\end{array}$ \\
\hline
\end{tabular}


Como fica patente na sistematização anterior (quadro 2), os problemas apresentados e discutidos nas Cimeiras ao longo dos anos inter-relacionam-se e são interdependentes, tendo como cenário os chamados desafios colocados aos sistemas educativos, decorrentes das mudanças emergentes no séc. XXI, de natureza política, socioeconómica e do conhecimento, envolvendo recorrentemente quatro tópicos: (i) a qualidade dos professores, apresentada como determinante para a melhoria do ensino-aprendizagem, associadas a políticas de apoio à aprendizagem e ao crescimento profissional dos professores para que cumpram eficazmente os reptos provenientes das competências necessárias para o séc. XXI; (ii) a promoção e apoio das lideranças; (iii) o ensino de qualidade para todos, considerando-se como critérios a excelência, a garantia de equidade e a inclusão; (iv) os sistemas de monitorização e avaliação da qualidade.

Há também uma continuidade na forma como, em cada cimeira, se agenda a discussão de um problema, aduzido como premente para a melhoria do desempenho dos sistemas educativos mundiais. Assim, inicialmente, procede-se a um enquadramento do problema, que inevitavelmente decorre de fenómenos que caracterizam o a atualidade e se projetam no futuro, apelando a ruturas com os modos 'habituais/tradicionais' de os sistemas prestarem o serviço educativo. Genericamente, essa primeira enunciação do problema assenta em argumentos que resistem a três provas (cf. DELVAUX, 2009): da “importância”, pelo estatuto de 'problema socialmente reconhecido' que lhe é reconhecido; da "acessibilidade”, por envolver a partilha de experiências, que tornam visíveis soluções apontadas; da "hierarquização", acautelando a emergência de outras questões sem o carácter de urgência do problema apresentado. Neste último plano volta de novo a ser importante o papel dos indicadores estatísticos para legitimar a priorização do problema face a outros.

Importa destacar, em função deste quadro argumentativo, as idiossincrasias nacionais, decorrentes dos contextos históricos, económicos, políticos e sociais de cada um, acompanham o sublinhar os problemas comuns. Tal ocorre por via do reconhecimento de que o mesmo problema (i) pode ter expressões distintas nos diferentes contextos e (ii) pode ter na sua origem ou agudização causas diversas. Os dois pressupostos ora enunciados, não são impeditivos de que durante a exploração dos problemas se prefigurem as causas mais comuns que estarão na sua origem e que, como se observa, vão sendo sistematicamente enfatizadas. Concomitantemente, vai sendo reforçada a ideia de que, independentemente das soluções a adotar por cada país, é basilar o reconhecimento do problema e a busca de linhas de atuação comuns que enquadrem a adoção ou revisão de políticas de âmbito nacional.

\section{Preconizações}

No que se refere às preconizações, é possível sistematizá-las tendo em consideração os problemas que supostamente enfrentam, bem como as linhas orientadoras da ação traçadas como respostas possíveis (Quadro 3). 
Quadro 3. Preconizações e linhas orientadoras de ação. Legenda: P1, P2, P3 e P4 - problematizações enunciadas no quadro $2 .^{10}$

\begin{tabular}{|c|c|c|c|c|c|c|}
\hline & \multirow{2}{*}{ Preconizações } & \multicolumn{4}{|c|}{ Problemas } & \multirow[t]{2}{*}{ Linhas orientadoras de ação (exemplos) } \\
\hline & & P1 & $\mathbf{P 2}$ & P3 & P4 & \\
\hline \multirow{3}{*}{ 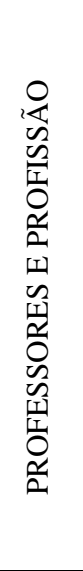 } & $\begin{array}{l}\text { Reconhecimento do } \\
\text { profissionalismo dos } \\
\text { professores }\end{array}$ & $\mathrm{X}$ & $\mathrm{X}$ & $\mathrm{X}$ & $\mathrm{X}$ & $\begin{array}{l}\text { * Aumentar o estatuto social dos professores } \\
\text { * Elevar a qualidade da profissão de ensino } \\
\text { * Promover liderança de alta qualidade e a confiança do } \\
\text { público }\end{array}$ \\
\hline & $\begin{array}{l}\text { Aposta na formação } \\
\text { inicial de elevado } \\
\text { nível }\end{array}$ & $\mathrm{X}$ & $\mathrm{X}$ & & $\mathrm{X}$ & $\begin{array}{l}\text { * Apostar na formação inicial conferente de grau académico } \\
\text { elevado, baseada em investigação } \\
\text { * Definir perfis profissionais e mudanças ao nível dos } \\
\text { programas de formação inicial de professores }\end{array}$ \\
\hline & $\begin{array}{l}\text { Investimento em } \\
\text { sistemas de DP }\end{array}$ & $\mathrm{X}$ & & $\mathrm{X}$ & $\mathrm{X}$ & $\begin{array}{l}\text { * Promover a supervisão pedagógica em estreita articulação } \\
\text { entre escolas e universidades } \\
\text { * Investir em programas de indução e tutoria para os novos } \\
\text { professores } \\
\text { * Desenvolver estratégias de Desenvolvimento profissional } \\
\text { permanente }\end{array}$ \\
\hline \multirow{4}{*}{ 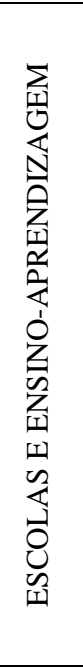 } & $\begin{array}{l}\text { Incremento da } \\
\text { autonomia das } \\
\text { escolas }\end{array}$ & $\mathrm{X}$ & & & $\mathrm{X}$ & * Reforçar a autonomia profissional \\
\hline & $\begin{array}{l}\text { Aposta na liderança } \\
\text { escolar }\end{array}$ & $\mathrm{X}$ & $\mathrm{X}$ & $\mathrm{X}$ & $\mathrm{X}$ & $\begin{array}{l}\text { * Apostar na preparação dos líderes escolares (liderança } \\
\text { pedagógica e liderança distribuída) } \\
\text { * Fortalecer a liderança nas escolas } \\
\text { * Dar prioridade à formação dos diretores }\end{array}$ \\
\hline & $\begin{array}{l}\text { Desenvolvimento de } \\
\text { uma cultura de } \\
\text { colaboração entre } \\
\text { professores e líderes } \\
\text { nas escolas }\end{array}$ & $\mathrm{X}$ & $\mathrm{X}$ & $\mathrm{X}$ & $\mathrm{X}$ & $\begin{array}{l}\text { * Promover a participação dos professores na definição dos } \\
\text { standards profissionais } \\
\text { * Incentivar a colaboração profissional } \\
\text { * Desenvolver uma cultura de colaboração entre professores e } \\
\text { líderes nas escolas }\end{array}$ \\
\hline & $\begin{array}{l}\text { Inovar os ambientes } \\
\text { de aprendizagem, } \\
\text { inclusivos para todos }\end{array}$ & & $\mathrm{X}$ & $\mathrm{X}$ & $\mathrm{X}$ & $\begin{array}{l}\text { * Ambientes mais centrados no aluno e personalizados para } \\
\text { levar as diferenças e interesses individuais em consideração } \\
\text { * criar condições para redesenhar o conteúdo, modernizar a } \\
\text { pedagogia e reestruturar o tempo e o espaço para a } \\
\text { aprendizagem. }\end{array}$ \\
\hline \multirow{2}{*}{ 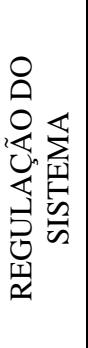 } & $\begin{array}{l}\text { Reforço dos sistemas } \\
\text { de avaliação de } \\
\text { desempenho dos } \\
\text { docentes }\end{array}$ & $\mathrm{X}$ & $\mathrm{X}$ & $\mathrm{X}$ & & $\begin{array}{l}\text { * Desenvolver sistemas de avaliação multidimensional } \\
\text { * Apostar na preparação dos avaliadores } \\
\text { * Usar a avaliação para apoiar a aprendizagem do professor }\end{array}$ \\
\hline & $\begin{array}{l}\text { Reforço de parcerias } \\
\quad \text { e alianças entre } \\
\text { governo e sindicatos }\end{array}$ & $\mathrm{X}$ & $\mathrm{X}$ & $\mathrm{X}$ & $\mathrm{X}$ & $\begin{array}{l}\text { * Envolver os sindicatos de professores no desenvolvimento e } \\
\text { implementação de políticas } \\
\text { * Integrar uma perspetiva de carreira para a profissão docente } \\
\text { na definição de políticas }\end{array}$ \\
\hline
\end{tabular}




\begin{tabular}{|c|c|c|c|c|c|l|}
\hline $\begin{array}{c}\text { Desenvolver } \\
\text { processos de } \\
\text { liderança horizontal } \\
\text { entre escolas e } \\
\text { sistemas }\end{array}$ & $\mathrm{X}$ & $\mathrm{X}$ & $\mathrm{X}$ & $\mathrm{X}$ & $\begin{array}{l}\text { * Estabelecer parcerias com a comunidade, agências sociais e } \\
\text { universidades } \\
\text { * Criar rede de partilha das melhores práticas entre escolas } \\
* \text { Desenvolver processos de liderança horizontal entre escolas e } \\
\text { sistemas, incluindo parcerias, redes e grupo }\end{array}$ \\
\hline
\end{tabular}

O racional das preconizações é frequentemente apoiado, como se exemplificará adiante, por dados provenientes do TALIS ou do PISA, cirurgicamente selecionados para sustentar a linha de argumentação seguida ou para, em caso de situações em que o consenso não é gerado, servirem para revelar que, apesar das divergências e controvérsias suscitadas entre os atores presentes, os resultados dos estudos geram fortes indicadores da trajetória a seguir. É também nos espaços de procura de soluções para os problemas enunciados que a produção de narrativas sobre práticas de sucesso ganha maior destaque, assinalando-se a validação do mérito destas práticas pelo nível de desempenho obtido nos estudos de larga escala promovidos pela OCDE.

As questões colocadas, e o modo como são propostas, convocam, regularmente os mesmos elementos para construir o problema e para a proposição das soluções. Os problemas são apresentados como transversais aos sistemas de ensino à escala global e, do mesmo modo, as causas apresentadas como sendo determinantes para a existência dos problemas, estão tendencial e continuamente associadas a um conjunto de questões. Desta forma, a procura das soluções é induzida por proposições causa-efeito, criando-se cenários em que as respostas a encontrar se devem focar na minoração ou superação dos défices apontados e na introdução de melhorias no que ainda é considerado insipiente. Assim, as preconizações avançadas que visam dar resposta aos problemas enunciados incidem em três planos: (i) professores e profissão, (ii) escolas e ensino-aprendizagem, (iii) regulação do sistema (ver quadro 3).

\section{Boas práticas}

Na formulação das soluções, recorre-se à análise de casos exemplares de países ou regiões cujos resultados são considerados reveladores de sucesso. Nas Cimeiras, as intervenções decorrem da apresentação de ‘boas práticas' de países previamente selecionados pela organização do evento, tidos como exemplares ou modelos inspiradores. Estes países são designados devido ao seu estatuto de 'sistema de elevada performance' ou apresentados como casos de referência decorrentes da análise de indicadores que atestam um crescimento acelerado e a rápida aproximação aos níveis de desempenho dos países de performance mais elevada. O nível de desempenho é, fundamentalmente, suportado pelos resultados alcançados no PISA, que permite estabelecer comparações entre os diferentes países ${ }^{11}$. Assim, o conhecimento pericial, gerado no quadro do PISA e amplamente difundido nas Cimeiras, é utilizado não só para informar sobre os resultados alcançados pelos países, como para demonstrar a sua evolução e, ainda, para legitimar a relevância das medidas adotadas pelos países apresentados como "modelo". A este conhecimento é, frequentemente, acrescentada informação proveniente de indicadores estatísticos procedentes de sistemas de monitorização 
nacionais, que são enunciados para demonstrar padrões de melhoria de desempenho, no contexto nacional em consonância com as orientações avançadas.

\section{Da centralidade do consenso e do recurso ao conhecimento pericial}

Como foi anteriormente referido, as Cimeiras contam com a participação de relatores, geralmente, académicos com vasta produção na área da educação. Nos momentos de discussão aberta aos audientes, procuram-se enunciar os consensos alcançados, que ganham o estatuto de caminhos a seguir, exortando-se os países participantes a assumir prioridades e compromissos de atuação em linha com esses consensos construídos ${ }^{12}$.

Contudo, nem sempre é possível a adesão e comprometimento de todos os parceiros em torno de uma solução. Nestes casos, a falta de consenso é atribuída a três ordens de razão: (i) à insuficiência de conhecimento existente - argumentando-se que não há investigação bastante para chegar a soluções válidas e consensuais, pelo que se torna necessário investir na procura de conhecimento nessa área; (ii) à necessidade de aprofundar a reflexão em torno do tema, assegurando-lhes assim um lugar nos assuntos a retomar na cimeira seguinte; (iii) à dissonância entre as posições defendidas e as pistas para onde o conhecimento existente aponta, de algum modo, minimizando os argumentos de quem intervém questionando as linhas de orientação que se procuram firmar (ver e.g. AS, 2013, 2016).

Esta última situação é visível quando existe controvérsia sobre as soluções a adotar e as suas implicações. A preconização a que se tenta chegar é posta perante a prova da “aceitabilidade” (Delvaux, 2009), sendo alvitrada a possibilidade de que a solução avançada e tida como eficaz em determinados contextos possa, em outros contextos, agravar o problema ou gerar novos problemas. Por exemplo, quando se discutem os modelos de avaliação de desempenho dos professores e as suas consequências, são enunciados, na discussão aberta à audiência, alguns dilemas, que são posteriormente minimizados com o argumento de que o TALIS revela claramente que os professores reconhecem a importância de terem feedback para melhorar e que muitos deles referem não ter acesso a esse feedback, pelo que, não sendo possível, ainda, assumir conjuntamente uma linha de atuação, se considera fundamental avançar na procura dessa solução, de modo a que os professores tenham acesso à informação que reclamam, sobre o seu desempenho (AS, 2013, 2016).

Também podemos encontrar exemplos em que a apresentação do conhecimento produzido nos estudos de larga escala da OCDE é usada para antecipar questões que possam vir a surgir nas Cimeiras. Por exemplo, face à eventual ‘alegação’ de inexistência de recursos para operacionalizar as medidas preconizadas, são avançados exemplos representativos de soluções que não dependerão do acréscimo de recursos ou implicarão somente uma gestão diferente dos recursos existentes. Ilustra esta situação a discussão do incremento salarial para reforço do estatuto socioprofissional dos professores, quando se enuncia que a solução encontrada num determinado país consistiu em manter o número de alunos em sala de aula em vez de o diminuir, ou que a opção passou por distribuir incentivos diferenciados pelos professores, em função de critérios pré-definidos, ou ainda a possibilidade de 'jogar' com a distribuição das cargas letivas por professor (ver e.g. AS, 2012). Desta forma, são enunciadas 
alternativas que passam pela procura de opções que garantam o equilíbrio financeiro em tempos de crise económica e de diminuição dos recursos disponíveis.

Significativamente, as Cimeiras encerram com o reforço dos principais consensos alcançados, que são considerados progressos assinaláveis para a educação, em geral, e para a profissão docente, em particular.

\section{Linhas interpretativas e conclusivas}

Este artigo procurou mostrar as Cimeiras sobre a profissão docente organizadas sob a égide da OCDE, como espaços de regulação transnacional das políticas públicas sobre a profissão docente. Tratam-se, assim, de fóruns em que se fabricam agendas em nome de um desígnio global de melhorar a qualidade dos sistemas educativos, marcados por problemas semelhantes e que carecem de resposta iminente. Nestes fóruns, os reclamados problemas e desafios que os sistemas educativos do e para o séc. XXI enfrentam, não só são extensíveis aos diversos contextos nacionais, como apelam à concertação na construção e adoção de medidas de orientação da ação. Neste sentido, são criadas condições para que atores provenientes de diferentes sectores e com distintos papéis e níveis de responsabilidade, possam refletir em conjunto, negociar e chegar a consensos.

Nestas páginas finais sintetizamos a principais linhas interpretativas e conclusivas, quer relacionadas (i) com os processos de coordenação postos em marcha pela OCDE através da criação e manutenção regular da Cimeira, quer - e com mais destaque - (ii) com as narrativas sobre a formação de professores e a profissão docente criadas no quadro do trabalho meditativo e exortativo nelas realizado. Incidiremos nos modos de regulação desencadeados, no papel regulador do conhecimento pericial, na fabricação de "uma solução para vários problemas” e na inscrição dos problemas-soluções para a profissão docente numa narrativa maior.

\section{A regulação da OCDE: a ativação do papel de regulação meditativa e exortativa}

As relações entre as autoridades públicas e os peritos, nacionais e internacionais, são geradas e geridas sob a égide da OCDE, a qual, depois de reunir essa variedade de atores em torno do estudo de um objeto singular, cria condições para que esses interajam regularmente, fixa e arbitra as relações entre esses diferentes mundos, de acordo com valores e regras por si determinadas.

O estudo das Cimeiras permite detetar o proeminente papel da OCDE na liderança dos processos de regulação transnacional, ativando contextos meditativos, trazendo para o palco cenários de perigo e estratégias de melhoria passíveis de orientar as políticas educativas no panorama mundial. As linhas de atuação erigidas neste contexto de construção de consensos proporcionado pelas Cimeiras, surgem como ancoragens para a assunção de prioridades e compromissos de ação a nível nacional, convergindo numa mesma direção, contribuindo para a itinerância de políticas (LINDBLAD; POPKEWITZ, 2004). Estamos em presença de 
processos de regulação soft, em que princípios de atuação são genericamente aceites por todos os intervenientes, cabendo a cada país identificar o que precisa de fazer e o modo como se propõe aproximar dos padrões enunciados.

\section{O papel regulador do conhecimento pericial}

O conhecimento pericial é o mais convocado nestes encontros sobre a profissão docente. Como veio sendo ilustrado, o uso dos instrumentos supranacionais de regulação pelo conhecimento é permanente, quer antecedendo o encontro - sendo selecionada (pela OCDE) a informação a disponibilizar aos participantes da cimeira na forma de documentos preparatórios -, quer servindo de 'argumentário', na identificação do problema e na sustentação das soluções a adotar. Mais ainda, em determinados momentos, o conhecimento pericial serve para esbater vozes discordantes que atrasam a adoção de linhas de atuação comuns ao porem à prova as problematizações e preconizações dos adversários.

O recurso permanente ao conhecimento produzido pelos instrumentos de regulação PISA e TALIS, enquanto informadores e legitimadores (ROBERTSON, 2012) nos processos de problematização e preconização, confirma e reforça a "confiança depositada pelos atores nacionais na OCDE, como uma organização pericial” (CARVALHO, 2016, p.672), o que garante uma aceitação tácita da mobilização do conhecimento produzido por estes estudos “como recurso válido e potencialmente útil” (ibidem).

Acompanham o exercício de procura de preconizações (por vezes explicitadas em simultâneo aquando do enquadramento do problema) a difusão de 'boas práticas', narradas por representantes dos governos nacionais, contextos sinalizados como exemplares atendendo aos lugares cimeiros que ocupam nos rankings internacionais construídos a partir dos resultados apurados em estudos de larga escala implementados e amplamente difundidos pela OCDE.

Gradualmente, assinala-se também o recurso ao conhecimento proveniente da investigação científica, parecendo, no entanto, intencional e estrategicamente selecionado como via para sustentar ideias veiculadas nos momentos de problematização e de preconização.

\section{Uma solução para vários problemas}

O estudo efetuado permite também detetar a transversalidade da adoção de duas outras estratégias na orientação dos trabalhos nos diversos encontros. Por um lado, torna-se evidente a tendência para a argumentação em torno de uma linha de ação surgir como resposta a mais do que um dos problemas enunciados ou agendados para serem trabalhados nos encontros. De forma geral, percebe-se que, para problemas diferentes, a solução apresentada se vai repetindo, e, desta forma, ganhando a força de 'caminho a seguir'. Por outro lado, a análise efetuada permite detetar a apresentação de um mesmo problema em momentos distintos e sob diferentes roupagens, o que contribui para que a linha de ação traçada vá surgindo transversalmente ao longo das Cimeiras como solução para problemas de natureza diversa. 
Da conjugação destas duas estratégias resulta, então, um movimento permanente de recordatória das linhas de atuação consensualmente assumidas nos encontros precedentes e o enaltecimento dos progressos entretanto alcançados pelos países participantes, reforçando a agenda política e verificando continuamente o cumprimento dos compromissos assumidos. Reforçam-se ideias que vêm servindo de ancoragem aos modos como os atores desenvolvem as suas políticas locais, potenciadas pelo reforço da abertura à participação de diferentes atores na definição e implementação das políticas. Neste sentido, é fortemente sublinhada a importância da articulação entre governos e associações profissionais, mormente quando se pretende garantir a disponibilização de sistemas de desenvolvimento profissional aos professores que atendam simultaneamente às necessidades dos sistemas e às preocupações dos professores.

\section{A inscrição dos problemas-soluções para a profissão docente numa narrativa maior}

A aproximação das narrativas produzidas nas Cimeiras ao imagético da OCDE 'Educação para o séc. XXI', é também uma das marcas que sobressai na análise das narrativas traduzidas nos documentos analisados. Entre outros aspetos, é amplamente difundida a ideia da necessidade de transposição de uma escola enciclopedista para uma escola potenciadora do desenvolvimento de competências, específicas e transversais, transferíveis e adaptáveis a diversos contextos, que se conjeturam como complexos, mutáveis e imprevisíveis. As preconizações avançadas colocam a tónica na necessidade de introduzir mecanismos que reforcem a qualidade da intervenção educativa nos primeiros níveis de educação e de escolaridade, diversifiquem a oferta de percursos de aprendizagem, com o alargamento de opções de cariz profissionalizante, em sintonia com os princípios da inclusão e de educação para todos presente no ideário da OCDE Educação XXI.

O discurso proferido ao longo das Cimeiras resulta numa certa circularidade, em que os problemas apresentados parecem apontar para as mesmas causas e para o mesmo quadro de soluções. Melhoria, autonomia, liderança, desenvolvimento profissional e garantia da qualidade parecem ser as chaves de um repertório continuamente retomado, conquanto se recorra a diferentes arranjos e sonoridades.

São, então, esgrimidos argumentos que procuram sustentar o lugar da escola na alavancagem da melhoria da qualidade dos sistemas educativos. Por um lado, sublinhando a importância da melhoria das escolas estar centrada em lógicas contextualizadas e não centralizadas, advogando-se o alargamento da autonomia das escolas e dos professores enquanto profissionais. Defende-se a criação de condições para que as escolas localmente encontrem as melhores soluções atendendo às suas especificidades, reconhecendo o estatuto dos professores enquanto profissionais altamente especializados. As alusões à premência de reforçar ou devolver às escolas e aos professores a 'autonomia perdida' é amplamente difundida, associando o alargamento da autonomia à necessidade de ter estruturas de liderança pedagógica, consideradas de excelência, na escola, mais desconcentradas (liderança distribuída) e que potenciem o desenvolvimento profissional e organizacional. 
O acréscimo de autonomia das escolas é, assim, acompanhado do enunciando da (i) necessidade de programas de aprendizagem e desenvolvimento ao longo da vida que confiram aos profissionais a possibilidade de desenvolverem competências profissionais para o desempenho de funções dentro e fora dos espaços letivos; (ii) do enaltecimento do papel do gestor escolar enquanto líder pedagógico, para quem se recomenda também uma aposta em formação especializada, argumentando-se que o investimento feito ao nível das lideranças escolares agilizará os efeitos a produzir à escala nacional. A estas duas ideias acresce uma terceira via, (iii) com o apelo ao reforço dos sistemas de monitorização e accountabilily, prevendo que escolas, gestores e professores sejam chamados a prestar contas, não sendo, no entanto, ainda visível a existência de tendências ou consensos alargados em torno dos consequentes processos de responsabilização.

Ao acréscimo da autonomia das escolas junta-se o reforço de novos padrões de profissionalismo e de profissionalidade docente, apropriados aos 'desafios' que a OCDE faz emergir da ficção criada em torno da agenda da educação para o século XXI. As preconizações, alimentadas no mainstream do pensamento educativo contemporâneo, advogam, então, ações tendentes ao reforço da autonomia profissional (em contexto organizacional), à participação dos professores na determinação dos standards profissionais, aos processos colaborativos e à criação de novos ambientes de aprendizagem. Sobressai, nesta expetativa de mudança, o papel ativo do professor, como agente (em interação com os colegas e em contextos de ação local) de uma reforma educativa - ou, como referem Pettersson; Molstad (2016, p. 343), a figura do "professor fênix", bem informado e desenvolvedor ativo da transformação educacional, a um tempo atores decisivos e, portanto, responsabilizáveis pela realização (ou não) da mudança da educação.

\section{Notas}

1. A AS apresenta-se como a organização líder para as questões da educação e da formação de professores no continente asiático, não estando, no entanto, fechada à participação de atores provenientes de outras partes do globo. Refere ter também o propósito de contribuir para o estreitamento das relações, em particular, com os Estados Unidos da América. Entre as diversas iniciativas e atividades que desenvolve, encontram-se os relatórios síntese produzidos a partir das Cimeiras anuais - Teacher Summits - organizadas sob a chancela da OCDE.

2. As Cimeiras ocorrem com uma periodicidade anual, sendo acolhidas ao longo dos anos por diferentes países.

3. Os temas apresentados no quadro replicam os títulos atribuídos pela AS aos relatórios das Cimeiras, que são fruto de uma reelaboração das designações que se encontram nos documentos preparatórios organizados pela OCDE.

4. No original 'Building a high-quality teaching profession. Lessons around the world”.

5. Disponível no endereço https://www.docencia.net.br/publicacoes

6. A abertura dos encontros, para além dos representantes da OCDE, a quem cabe fazer um primeiro enquadramento geral das preocupações em torno das quais se organiza a Cimeira, integra também simbolicamente um painel de representantes das estruturas governamentais de países participantes, com cargos da mais alta responsabilidade na área da educação (eg. ministros, secretários gerais) e delegações de organizações profissionais, em particular representantes da federação internacional de professores - Education International (EI). A participação destes últimos atores é sublinhada desde o primeiro encontro como um avanço na diversificação dos atores convocados para o debate das questões educativas. Entre os países participantes, com intervenção formal nas Cimeiras, destacam-se EUA, Finlândia, Reino Unido, Nova Zelândia que estiveram presentes em quase todos os encontros entre 2011 e 2017. Assinala-se ainda um aumento significativo no número de países com participação fornal nas Cimeiras em 2015, 2016 e 2017. 
7. Entre estes académicos de mérito reconhecido, provenientes de universidades de referência e/ou consagrados por publicações de referência (e.g. handbooks), citam-se a título de exemplo Ben Levin (University of Toronto), Fernando Reimers (University of Harvard), Linda Darling-Hammond (university of Stanford), Michael Fullan (University of Toronto).

8. Entre as experiências consideradas bem-sucedidas e os casos-exemplo que são enaltecidos nas Cimeiras, destacam-se os países asiáticos, como o Japão, Singapura e a República Popular da China; casos de países europeus, como a Finlândia, a Alemanha, o Reino Unido e a Holanda; países norte-americanos, como os EUA e o Canadá; e também a Nova Zelândia (Oceânia).

9. São designados como 'starters' ou desencadeadores da discussão que será aberta à audiência.

10. Para mais detalhe ver Almeida; Viana (2019).

11. Os princípios ou pressupostos defendidos pelos intervenientes surgem também apoiados no conhecimento produzido por outros estudos da OCDE, como é o caso do recurso ao conhecimento gerado a partir do TALIS, cujos resultados permitem evidenciar a força de uma ideia que se pretende difundir, ao revelar como uma medida é bem acolhida pelos professores ou como encorpa uma preocupação de um número alargado de respondentes.

12. Como referido a propósito da análise dos papéis desempenhados pelos atores, a partir de 2013, o papel dos que habitualmente vão intervindo na qualidade de relatores - os académicos, é alargado ao papel de formadores. Desta forma, ao conhecimento pericial que circula nos momentos de problematização e preconização, junta-se o conhecimento proveniente da investigação científica, contribuindo para a apropriação e partilha de quadros cognitivos a ser mobilizados pelos diferentes atores na análise e na interpretação dos fenómenos em debate.

\section{Referências}

ALMEIDA, M.; VIANA, J. Problematizações e preconizações internacionais sobre formação de professores. Relatório relativo ao projeto "Políticas públicas para a melhoria do ensino médio: socialização científica, tradução e transferência de resultados”, Meta1- Ação 1.2 - Estado da arte e produção do conhecimento, 2019.

AMADO, J. Manual de Investigação Qualitativa em Educação. Coimbra: Imprensa da Universidade de Coimbra, 2013.

BARDIN, L. Análise de conteúdo. Lisboa: Edições 70, 2009.

BARROSO, J. O Estado, a educação e a regulação das políticas públicas. Educação \& Sociedade, Vol. 26, nº 92, p. 725-751, 2005.

BEIJAARD, D.; MEIJER, P.; MORINE-DERSHIMER; G.; TILLEMA, H. Trends and themes in teachers' working and learning environment. In: Beijard, D.; Meijer, P.; Morine-Dershimer, G.; Tillema, H. (Eds.). Teacher professional development in changing conditions. Netherland: Springer, 2005, p.9-26.

BRADFORD, N. The OECD's local turn. In: MAHON, R.; MCBRIDE, S. (Eds.). The OECD and transnational governance. Vancouver: UBC Press, 2008, p. 134-151.

CARVALHO, L. M. Intensificação e sofisticação dos processos da regulação transnacional em educação: o caso do PISA. Educ. Soc., vol. 37, n. 136, p. 669-683, 2016

CARVALHO, L. M.; NORMAND, R. Introduction. In: NORMAND, R.; LIU, M.; CARVALHO, L. M.; OLIVEIRA, D. A.; LEVASSEUR, L. (Eds.). Education Policies and the Restructuring of the Educational Profession. Global and Comparative Perspectives. Heidelberg: Springer Singapura, 2018, p. 1-12.

COUTINHO, C. Metodologia de Investigação em Ciências Sociais e Humanas: Teoria e Prática. Coimbra: Almedina, 2013.

DELVAUX, B. Qual é o papel do conhecimento na acção pública? Educ. Soc., vol. 30, n. 109, p. 959-985, 2009. 
DJELIC, M.-L.; SAHLIN-ANDERSON, K. Institutional dinamics in a re-ordering world. In: DJELIC, M.-L.; SAHLIN-ANDERSON, K. (Eds.). Transnational governance. Institutional dinamics of regulation. Cambridge: Cambridge University Press, 2006, p. 375-397.

ERICKSON, F. Qualitative methods in research on teaching. In: WITTROCK, M. C. (Ed.). Handbook of research on teaching. New York, NY: Macmillan, 1986.

GHIGLIONE, J.L.B.; CHABROL, C.; TROGON, A. Manuel d'analyse de contenu. Paris: A. Colin, 1980

JACOBSSON, B. Regulated regulators. In: DJELIC, M. L.; SAHLIN-ANDERSON, K. (Eds.). Transnational governance. Cambridge: Cambridge University Press, 2006, p. 205-224.

LEUZE, K.; MARTENS, K.; RUSCONI, A. Introduction. In: MARTENS, K.; A. RUSCONI, A.; LEUZE, K. (eds). New Arenas of Education Governance. London: Routledge, 2007, p. 3-15.

LINDBLAD, S.; POPKEWITZ, T.S. Educational Restructuring: (Re) thinking the problematic of reform. In: LINDBLAD, S.; POPKEWITZ, T. S. (eds.), Educational Restructuring: Perspetives on Traveling Policies. IAP, 2004.

MARCUSSON, M. The Organization for Economic Cooperation and Development as ideational artist and arbitrator. In: REINALDA, B.; VERBEEK, B. (eds.), Decision Making Within International Organisations. London: Routledge, 2004, p. 90-105.

OZGA, J.; LINGARD, B. Globalisation, education policy, and politics. In: LINGARD, B.; OZGA, J. (eds.) The Routlege/Falmer in Education Policy and Politics. New York: Routledge, 2007.

PETTERSSON, D.; MOLSTAD, C. PISA teachers: the hope and the happening of educational development. Educ. Soc. Vol. 37, n. 136, p. 629-45, 2016.

RIZVI, F.; LINGARD, B. Globalisation and the changing nature of the OECD's educational work. In: LAUDER, H.; BROWN, P.; DILLABOUGH, J. A.; HALSEY, A. H. (eds.), Education, Globalisation and Social Change. Oxford: Oxford University Press, 2006.

ROBERT, A.; BOUILLAGUET, A. (2002). L'analyse de contenu (2 $2^{\mathrm{a} e d) . ~ P a r i s: ~ P u f, ~} 2002$.

ROBERTSON, S. Placing' teachers in global governance agendas. Comparative Education Review, vol. 56, n. 3, p. 584-607, 2012.

\section{Fontes}

ASIA SOCIETY. Improving teacher quality around the world. The 2011 International Summit on the Teaching Profession. New York: Asia Society, 2011. Relatório disponível em: AsiaSociety.org/teachingsummit

ASIA SOCIETY. Teaching and leadership for the twenty-first century. The 2012 International Summit on the Teaching Profession. New York: Asia Society, 2012. Relatório disponível em: AsiaSociety.org/teachingsummit

ASIA SOCIETY. Teacher Quality. The 2013 International Summit on the Teaching Profession. New York: Asia Society, 2013. Relatório disponível em: AsiaSociety.org/teachingsummit

ASIA SOCIETY. Excellence, Equity, and Inclusiveness. High Quality Teaching for All. The 2014 International Summit on the Teaching Profession. Wellington, New Zealand: Asia Society, 2014. Relatório disponível em: AsiaSociety.org/teachingsummit

ASIA SOCIETY. Implementing Highly Effective Teacher Policy and Practice. The 2015 International Summit on the Teaching Profession. Banff, Canadá: Asia Society, 2015. Relatório disponível em: AsiaSociety.org/teachingsummit 
ASIA SOCIETY. Teachers' professional learning and growth: creating the conditions to achieve quality teaching for excellent learning outcomes. The 2016 International Summit on the Teaching Profession. Berlim, Alemanha: Asia Society, 2016. Relatório disponível em: AsiaSociety.org/teachingsummit

ASIA SOCIETY. Empowering and Enabling Teachers to Deliver Improved Equity and Outcomes for All. The 2017 International Summit on the Teaching Profession. Edimburg, Escócia: Asia Society, 2017. Relatório disponível em: AsiaSociety.org/teachingsummit

OCDE. Preparing Teachers and Developing School Leaders for the 21st Century. Lessons from around the world. OECD Publishing, 2012. dx.doi.org/10.1787/9789264174559-en

OCDE. Teachers for the 21st Century. Using Evaluation to Improve Teaching. OECD Publishing, 2013. https://doi.org/10.1787/9789264193864-en

OCDE. Empowering and Enabling Teachers to Improve Equity and Outcomes for All. OECD Publishing, 2017. https://doi.org/10.1787/9789264273238-en

SCHLEICHER, A. Building a High-Quality Teaching Profession. Lessons from around the world. OECD Publishing, 2011. http://dx.doi.org/10.1787/9789264113046-en

SCHLEICHER, A. Equity, Excellence and Inclusiveness in Education Policy Lessons from Around the World. OECD Publishing, 2014. https://doi.org/10.1787/9789264214033-en

SCHLEICHER, A. Schools for 21st-Century Learners: Strong Leaders, Confident Teachers, Innovative Approaches. OECD Publishing, 2015. http://dx.doi.org/10.1787/9789264231191-en

SCHLEICHER, A. Teaching Excellence through Professional Learning and Policy Reform: Lessons from Around the World. International Summit on the Teaching Profession. Paris: OECD Publishing, 2016. http://dx.doi.org/10.1787/9789264252059-en

Website Asia Society Partnership for Global Learning: https://asiasociety.org/

Anexo 1 - Atores com participação formal nas Cimeiras

\begin{tabular}{|c|c|c|c|}
\hline Ano & Painel de Abertura & $\begin{array}{l}\text { Framing /enquadramento } \\
\text { e problematização inicial }\end{array}$ & Partilha de experiências \\
\hline 2011 & $\begin{array}{l}\text { - U.S. Secretary of Education } \\
\text { - General Secretary of Education } \\
\text { International (federação de } \\
\text { professores) } \\
\text { - Education Director of OECD }\end{array}$ & $\begin{array}{l}\text { OCDE (Andreas } \\
\text { Schleicher) }\end{array}$ & $\begin{array}{l}\text { EUA, Finlândia, Hong } \\
\text { Kong, Noruega, Reino } \\
\text { Unido } \\
\text { República Popular da } \\
\text { China } \\
\text { Singapura }\end{array}$ \\
\hline 2012 & $\begin{array}{l}\text { - U.S. Secretary of Education } \\
\text { - OECD Deputy Secretary General } \\
\text { - General Secretary of Education } \\
\text { International }\end{array}$ & $\begin{array}{l}\text { OCDE (Andreas } \\
\text { Schleicher) }\end{array}$ & $\begin{array}{l}\text { EUA, Finlândia } \\
\text { Japão, Ontario (Canada) } \\
\text { Shanghai (China) }\end{array}$ \\
\hline 2013 & $\begin{array}{l}\text { - Dutch Minister of Education, Culture } \\
\text { and Science } \\
\text { - General Secretary of Education } \\
\text { International } \\
\text { - Director Education and Skills OECD }\end{array}$ & $\begin{array}{l}\text { Dutch Minister of } \\
\text { Education, Culture and } \\
\text { Science } \\
\text { OCDE (Andreas } \\
\text { Schleicher) } \\
\text { General Secretary of EI } \\
\end{array}$ & $\begin{array}{l}\text { Alemanha } \\
\text { EUA } \\
\text { Holanda } \\
\text { Japão } \\
\text { Nova Zelândia } \\
\text { Suécia } \\
\end{array}$ \\
\hline 2014 & $\begin{array}{l}\text { - New Zealand Deputy Prime Minister } \\
\text { - New Zealand Minister of Education } \\
\text { - U.S. Secretary of Education }\end{array}$ & $\begin{array}{l}\text { New Zealand Minister of } \\
\text { Education }\end{array}$ & $\begin{array}{l}\text { Alemanha } \\
\text { Escócia (Reino Unido) } \\
\text { Estónia }\end{array}$ \\
\hline
\end{tabular}




\begin{tabular}{|c|c|c|c|}
\hline & $\begin{array}{l}\text { - Dutch Minister of Education, Culture } \\
\text { and Science } \\
\text { - Director Education and Skills OECD } \\
\text { - General Secretary of Education } \\
\text { International }\end{array}$ & $\begin{array}{l}\text { OECD - Director } \\
\text { Education and Skills } \\
\text { General Secretary of EI } \\
\text { OCDE (Andreas } \\
\text { Schleicher) } \\
\text { General Secretary of EI } \\
\text { CEO of the Centre for } \\
\text { Strategic Education in } \\
\text { Australia }\end{array}$ & $\begin{array}{l}\text { Finlândia } \\
\text { Nova Zelândia } \\
\text { Singapura }\end{array}$ \\
\hline 2015 & $\begin{array}{l}\text { - Ministro da Educação de Alberta e } \\
\text { Presidente do Conselho de Ministros } \\
\text { da Educação do Canadá } \\
\text { - Presidente da Learning Partnership e } \\
\text { General Counsel of Deloitte } \\
\text { - OECD Deputy Secretary General } \\
\text { - General Secretary of Education } \\
\text { International } \\
\text { - Senior Consultant to Education } \\
\text { International } \\
\text { - CEO of the Centre for Strategic } \\
\text { Education in Australia }\end{array}$ & $\begin{array}{l}\text { OCDE - Deputy Secretary } \\
\text { General } \\
\text { General Secretary of EI } \\
\text { CEO of the Centre for } \\
\text { Strategic Education in } \\
\text { Australia }\end{array}$ & $\begin{array}{l}\text { Austrália, Canadá } \\
\text { China, Escócia (Reino } \\
\text { Unido) } \\
\text { Estónia, EUA } \\
\text { Finlândia, Holanda } \\
\text { Hong Kong, Japão } \\
\text { Londres (Reino Unido) } \\
\text { Nova Zelândia, Singapura } \\
\text { Suécia, Suíça } \\
\text { Xangai }\end{array}$ \\
\hline 2016 & $\begin{array}{l}\text { - Presidente da Standing Conference } \\
\text { of the Ministers of Education and } \\
\text { Cultural Affairs (KMK) e Bremen } \\
\text { Senator for Children and Education } \\
\text { - OECD Deputy Secretary General } \\
\text { - General Secretary of Education } \\
\text { International } \\
\text { - Presidente do Conselho de Ministros } \\
\text { da Educação do Canadá } \\
\text { - Director Education and Skills and } \\
\text { Special Advisor on Education Policy } \\
\text { to the Secretary General, OECD } \\
\text { - Senior Consultant to Education } \\
\text { International } \\
\text { - CEO of the Centre for Strategic } \\
\text { Education in Australia }\end{array}$ & $\begin{array}{l}\text { OCDE - Deputy Secretary } \\
\text { General } \\
\text { General Secretary of EI } \\
\text { OCDE (Andreas } \\
\text { Schleicher) } \\
\text { CEO of the Centre for } \\
\text { Strategic Education in } \\
\text { Australia }\end{array}$ & $\begin{array}{l}\text { Alemanha, Áustria } \\
\text { Bélgica, Canadá } \\
\text { Dinamarca, Escócia, } \\
\text { Eslovênia } \\
\text { EUA } \\
\text { Finlândia, Holanda } \\
\text { Japão } \\
\text { Letónia } \\
\text { Luxemburgo, Noruega } \\
\text { Nova Zelândia } \\
\text { Polónia } \\
\text { Reino Unido } \\
\text { República Checa } \\
\text { Shangai, Singapura } \\
\text { Suécia, Suíça }\end{array}$ \\
\hline 2017 & $\begin{array}{l}\text { - Minister of State for School } \\
\text { Standards, UK Department for } \\
\text { Education } \\
\text { - Deputy First Minister and Cabinet } \\
\text { Secretary for Education and Skills, } \\
\text { Scotland } \\
\text { - General Secretary of Education } \\
\text { International }\end{array}$ & $\begin{array}{l}\text { OCDE (Andreas } \\
\text { Schleicher) } \\
\text { General Secretary of EI } \\
\text { Secretary General of the } \\
\text { Standing Conference of } \\
\text { Ministers of Education and } \\
\text { Cultural Affairs of the } \\
\text { Länder of the Federal } \\
\text { Republic of Germany }\end{array}$ & $\begin{array}{l}\text { Austrália, Canadá } \\
\text { China, Dinamarca, Escócia } \\
\text { Eslovénia, Estónia, EUA, } \\
\text { Finlândia, Holanda, } \\
\text { Inglaterra, Letónia } \\
\text { Nova Zelândia } \\
\text { País de Gales, Polónia } \\
\text { Portugal, Reino Unido } \\
\text { Singapura, Suécia, Suiça }\end{array}$ \\
\hline
\end{tabular}




\begin{tabular}{|l|l|l|l|}
\hline & $\begin{array}{l}\text { CEO of the Centre for } \\
\text { Strategic Education in } \\
\text { Australia }\end{array}$ & \\
\hline
\end{tabular}

\section{Correspondência}

Marta Mateus de Almeida: É doutora em Educação pela Universidade de Lisboa. Atualmente é Professora Auxiliar do Instituto de Educação da mesma Universidade, exercendo atividade como pesquisadora integrada na Unidade de Investigação e Desenvolvimento em Educação e Formação (UIDEF), no Grupo de Investigação Políticas de Educação e Formação.

E-mail: mialmeida@ie.ulisboa.pt

Joana Viana: É doutora em Educação, na área de Teoria e Desenvolvimento Curricular, pela Universidade de Lisboa. Professora Auxiliar Convidada no Instituto de Educação da Universidade de Lisboa e pesquisadora colaboradora na Unidade de Investigação e Desenvolvimento em Educação e Formação (UIDEF) no Grupo de Investigação Currículo, Formação de Professores e Tecnologias.

E-mail: jviana@ie.ulisboa.pt

Luís Miguel Carvalho: É Professor catedrático no Instituto de Educação da Universidade de Lisboa (IEULisboa), onde, no presente, exerce funções de Diretor, de Coordenador da Unidade de Investigação e Desenvolvimento em Educação e Formação (UIDEF) e de coordenador do Doutoramento em Educação, na especialização de Administração e Política Educacional. Ao longo da última década vem estudando e publicando, com regularidade, sobre o PISA e os processos de multirregulação educação.

E-mail: lmcarvalho@ie.ulisboa.pt

Texto publicado em Currículo sem Fronteiras com autorização dos autores 